\title{
AVALIAÇÃO VISUAL RÁPIDA DE RIOS URBANOS: O CASO DO BAIXO CURSO DA BACIA HIDROGRÁFICA DO RIO REIS MAGOS E DO RIO JACARAÍPE, ESPÍRITO SANTO
}

Fabricio Holanda do Nascimento Universidade Federal do Espírito Santo (UFES), Departamento de Geografia fabricio.climatologia2015@gmail.com

Amanda Fernandes Silva Universidade Federal do Espírito Santo (UFES), Departamento de Geografia amandafernandeslibra@gmail.com

Silênia de Azevedo Silveira Rangel Universidade Federal do Espírito Santo (UFES), Departamento de Letras sileniarangel@gmail.com

Fernanda Barboza dos Santos Universidade Federal do Espírito Santo (UFES), Departamento de Geografia fernandabarboza1987@hotmail.com

\begin{abstract}
RESUMO
Este trabalho objetiva fazer uma avaliação socioambiental por meio do método dos Protocolos de Avaliação Rápida (PAR), no baixo curso da bacia hidrográfica do Rio Reis Magos e na foz do Rio Jacaraípe. Para tanto, foram desenvolvidas leituras bibliográficas acerca das principais teorias aqui abordadas, a exemplo dos sistemas fluviais. Além disso, foi confeccionado um PAR para a avaliação visual dos corpos d'água supracitados com quatorze questões a serem avaliadas e analisadas, das quais envolvem características naturais e sociais em torno desses rios. Os resultados foram satisfatórios, pois permitiram inferir uma série de considerações sobre os rios avaliados e, assim, produzir material científico que possa colaborar com os órgãos gestores e a sociedade nos planejamentos urbano e ambiental.
\end{abstract}

Palavras-chave: Sistemas fluviais. Recursos hídricos. Planejamento urbano. Planejamento ambiental. Gestão ambiental.

\section{RAPID VISUAL EVALUATION OF URBAN RIVERS: THE CASE OF THE LOW HYDROGRAPHIC BASIN OF RIO REIS MAGOS AND RIO JACARAÍPE, ESPÍRITO SANTO}

\begin{abstract}
This paper aims to make a social and environmental assessment through the Rapid Assessment Protocols (RAP) method, in the low course of the Reis Magos river basin and in the Jacaraípe river mouth. To this end, bibliographic readings were developed about the main theories approached here, such as river systems. In addition, a PAR was made for the visual assessment of the above bodies of water with fourteen questions to be evaluated and analyzed, which involve natural and social characteristics around these rivers. The results were satisfactory, as it allowed us to infer a series of considerations about the evaluated rivers and, thus, produce scientific material that can collaborate with the governing bodies and society in urban and environmental planning.
\end{abstract}

Keywords: River systems. Water resources. Urban planning. Environmental planning. Environmental management.

\begin{tabular}{|c|c|}
\hline Caminhos de Geografia & Uberlândia \\
\hline
\end{tabular}


Avaliação visual rápida de rios urbanos: o caso do baixo curso da bacia hidrográfica do Rio Reis Magos e do Rio Jacaraípe, Espírito Santo
Fabricio Holanda do Nascimento Amanda Fernandes Silva Silênia de Azevedo Silveira Rangel Fernanda Barboza dos Santos

\section{INTRODUÇÃO}

A ação do homem sobre os elementos da natureza pode ser evidenciada sobre o relevo, a vegetação, o clima e também sobre os sistemas fluviais. Nesse contexto, as bacias hidrográficas, principais unidades de planejamento e de gestão geoambiental, são consideradas unidades sistêmicas e de integração entre as cidades e a natureza (CUNHA, 2008).

As cidades passam por diversas transformações, ao longo do tempo, em seu padrão de uso e em sua cobertura da terra, gerando diversas consequências sobre a sociedade, o clima e o sistema fluvial. Assim:

As cidades mostram, ao longo do tempo, transformações no uso e na ocupação do solo, com sucessivos estágios de crescimento espacial e de urbanização, desde a fase do pré-urbano, até o urbano avançado [...] com implicações no nível de degradação da bacia (CUNHA, 2008, p. 329).

Além disso, segundo a autora (op. cit.), os problemas que afetam os sistemas naturais, em especial os sistemas fluviais, são muito mais frequentes em países em desenvolvimento localizados nos trópicos, sobretudo, devido às suas características do processo de urbanização que, em muitos casos, algumas cidades "[...] foram criadas com a função de um ponto de apoio ao comércio regional ou de centro administrativo por força colonial ou regional" (p. 329). Esse fator deve-se ao rápido processo de urbanização, que esses países passaram e ainda passam, sem considerar suficientemente os elementos da natureza e as condições do sítio local.

Partindo desse panorama, de acordo com Gregory (2006), ao longo da história, a humanidade vem desempenhando um papel ativo e importante, no que se refere às transformações e às modificações dos ambientes naturais e, em especial, dos ambientes fluviais. Esse cenário requer do pesquisador um olhar sistêmico.

Ademais, na perspectiva de Ashmore (2015), a preocupação central da geomorfologia é com os processos naturais e com as formas terrestres. "Porém, questões relacionadas aos rios urbanos envolvem uma série de fatores que perpassam à escala das ciências naturais, havendo necessidade de compreender os aspectos sociais e culturais que permeiam a sociedade, conceito este denominado de sociogeomorfologia" (p. 150). O autor (op. cit.) ainda expressa:

\footnotetext{
Minha proposição para a sociogeomorfologia é que a compreensão e a explicação geomorfológicas podem ser úteis em algumas circunstâncias, adotando-se o conceito de co-produção e de sistemas socionaturais de formas terrestres, embora a forma exata de análise dependerá da evolução de posições filosóficas e direções de desenvolvimento da ideia (ASHMORE, 2015, p. 150, "tradução nossa").
}

Nesse aspecto, os estudos dos sistemas fluviais dar-se-ão como coprodução sistêmica, visando auxiliar ao pesquisador para um melhor entendimento do fenômeno investido, como também garantindo aos gestores um instrumental mais adequado para a conservação e para a preservação dos ambientes fluviais.

Conforme a autora Charlton (2008):

Um sistema é uma coleção de objetos relacionados e os processos que vinculam esses objetos. Nos sistemas fluviais, objetos como encostas, rede de canais e várzeas estão interligados pelos processos a rede de canais e as planícies de inundação são interligadas pelos processos que movem a água e os sedimentos entre eles. Em comum com outros sistemas, o sistema fluvial é hierárquico, em que existem sub-sistemas integrados operando dentro dele (CHARLTON, 2008, p. 10, "tradução nossa").

Dessa maneira, a conservação e a preservação dos sistemas fluviais são relevantes por serem sistemas importantes na manutenção da vida e de diversos outros sistemas, seja ambiental, seja social, seja econômico (ROSA; MAGALHÃES JUNIOR, 2019). Nesse contexto, a importância dos sistemas fluviais se

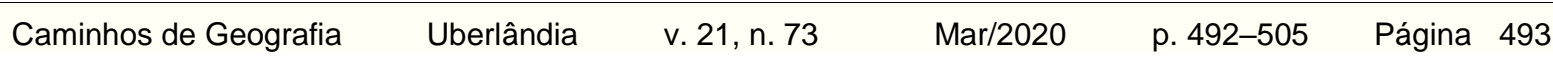


Avaliação visual rápida de rios urbanos: o caso do baixo curso da bacia hidrográfica do Rio Reis Magos e do Rio Jacaraípe, Espírito Santo
Fabricio Holanda do Nascimento Amanda Fernandes Silva Silênia de Azevedo Silveira Rangel Fernanda Barboza dos Santos

dá em vários âmbitos, como, "[...] o ciclo hidrológico, o transporte de sedimentos, a regulação de ecossistemas, o abastecimento público e as atividades agrícolas e industriais" (op. cit., p. 442).

Diante disso, Hannaford et al. (1997) desenvolveram uma metodologia denominada Protocolo de Avaliação Rápida (PAR), com o intuito de avaliar a diversidade de habitats. Essa metodologia foi reavaliada e modificada por Callisto et al. (2002) para avaliar e monitorar os sistemas fluviais, de aplicação relativamente fácil, considerando os ajustes necessários para cada local. Em sua concepção, o PAR foi composto por 22 questões que elencam o nível de impacto das atividades antrópicas sobre os recursos hídricos e os níveis de conservação dos ambientes fluviais.

Nesse âmbito, o Protocolo de Avaliação Rápida (PAR) é uma importante ferramenta para o desenvolvimento de programas de monitoramento ambiental. Essa ferramenta permite análises apuradas e de pouco custo, levando em consideração diversos indicadores ambientais que extrapolam a questão da qualidade e da disponibilidade da água, por exemplo, as relações entre os corpos d'água e a população residente nas proximidades dos rios.

Em face a esse cenário, este trabalho tem o objetivo de fazer uma avaliação rápida, por meio de um PAR, em quatro segmentos de dois importantes rios da Região Metropolitana da Grande Vitória (RMGV), Estado do Espírito Santo. Um segmento na foz do Rio Jacaraípe, Município da Serra; e três segmentos no baixo curso do Rio Reis Magos, entre os Municípios da Serra e de Fundão, relacionando os resultados com os diferentes contextos de uso e de cobertura da Terra nesses Municípios. Especificamente, pretende-se discutir a aplicabilidade e as potencialidades do PAR em rios capixabas, além da sua importância no monitoramento e na gestão dos recursos hídricos em ambientes urbanos.

Embora na sua origem o PAR tenha sido composto por 22 parâmetros, nessa pesquisa foram elencados apenas 14 deles. Esse ajuste foi necessário devido ao fato de alguns dos parâmetros não terem sido encontrados ou de difícil visualização. Tal ocorrência se deu em virtude das dimensões dos trechos analisados, a exemplo do parâmetro "tipo de fundo", "oleosidade do fundo" etc.

Em face disso, essa pesquisa torna-se importante por possibilitar a geração de conhecimento científico dos cursos d'água em estudo, haja vista pouca análise sobre os rios supracitados, podendo contribuir com o fornecimento de material acadêmico aos gestores e à sociedade acerca das reais condições dos rios avaliados e gerando subsídio aos planejamentos urbano e à gestão ambiental. Além disso, é importante essa produção sobre a área de estudo com a utilização de uma estrutura teórica e de uma estrutura metodológica fornecida pela ciência geográfica.

\section{METODOLOGIA}

\section{Localização e caracterização da área de estudo}

A área de estudo refere-se à foz do Rio Jacaraípe, Município da Serra, Estado do Espírito Santo e ao baixo curso da bacia hidrográfica do Rio Reis Magos (BHRRM), Municípios da Serra e de Fundão respectivamente. Essa bacia possui uma área de aproximadamente $1.127 \mathrm{~km}^{2}$ e abrange os Municípios de Santa Teresa, de Santa Leopoldina, de Ibiraçu, de Fundão, de Aracruz, de Serra e uma pequena área na porção norte do Município de Vitória (Figura 1).

Do ponto de vista geomorfológico, a BHRRM possui altitudes que variam de -2 a altitudes acima de 1000 metros, notadamente em Santa Teresa, localizada na região Central Serrana do Espírito Santo. A compartimentação do relevo varia de Planície Costeira, Tabuleiros Costeiros a Patamares Escalonados do Sul Capixaba, áreas mais elevadas da bacia (IJSN, 2012).

No que se refere à declividade, a área de estudo apresenta classes clinográficas que vão de plano a forte montanhoso, considerando a metodologia da Empresa Brasileira de Pesquisas Agropecuárias EMBRAPA

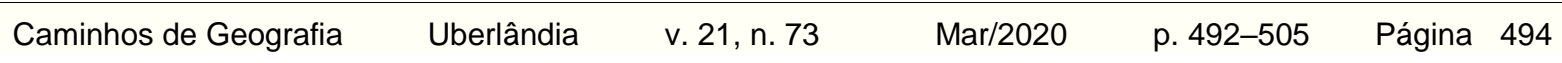


Avaliação visual rápida de rios urbanos: o caso do baixo curso da bacia hidrográfica do Rio Reis Magos e do Rio Jacaraípe, Espírito Santo
Fabricio Holanda do Nascimento Amanda Fernandes Silva Silênia de Azevedo Silveira Rangel Fernanda Barboza dos Santos

(1999), e com base no Modelo Digital de Elevação (MDE) Topodata de 30 metros de resolução espacial, disponível no site do Instituto Nacional de Pesquisas Espaciais (INPE) (Figura 2).

Em relação ao uso e à cobertura da terra (

Figura 3), segundo a classificação do Instituto de Defesa Agropecuária e Florestal do Espírito Santo (IDAF, 2016), com base na foto aérea de 2012/2015, a BHRRM é caracterizada por áreas expressivas de mata nativa, correspondendo a aproximadamente $32 \%$ da área total da bacia, seguido de pastagens, com cerca de $25 \%$ do total (Tabela 1). No entanto, no baixo curso do Rio Reis Magos, bem como na foz do Rio Jacaraípe, a área urbana é predominante, em detrimento da supressão de áreas verdes.

Figura 1 - Localização da área de estudo.

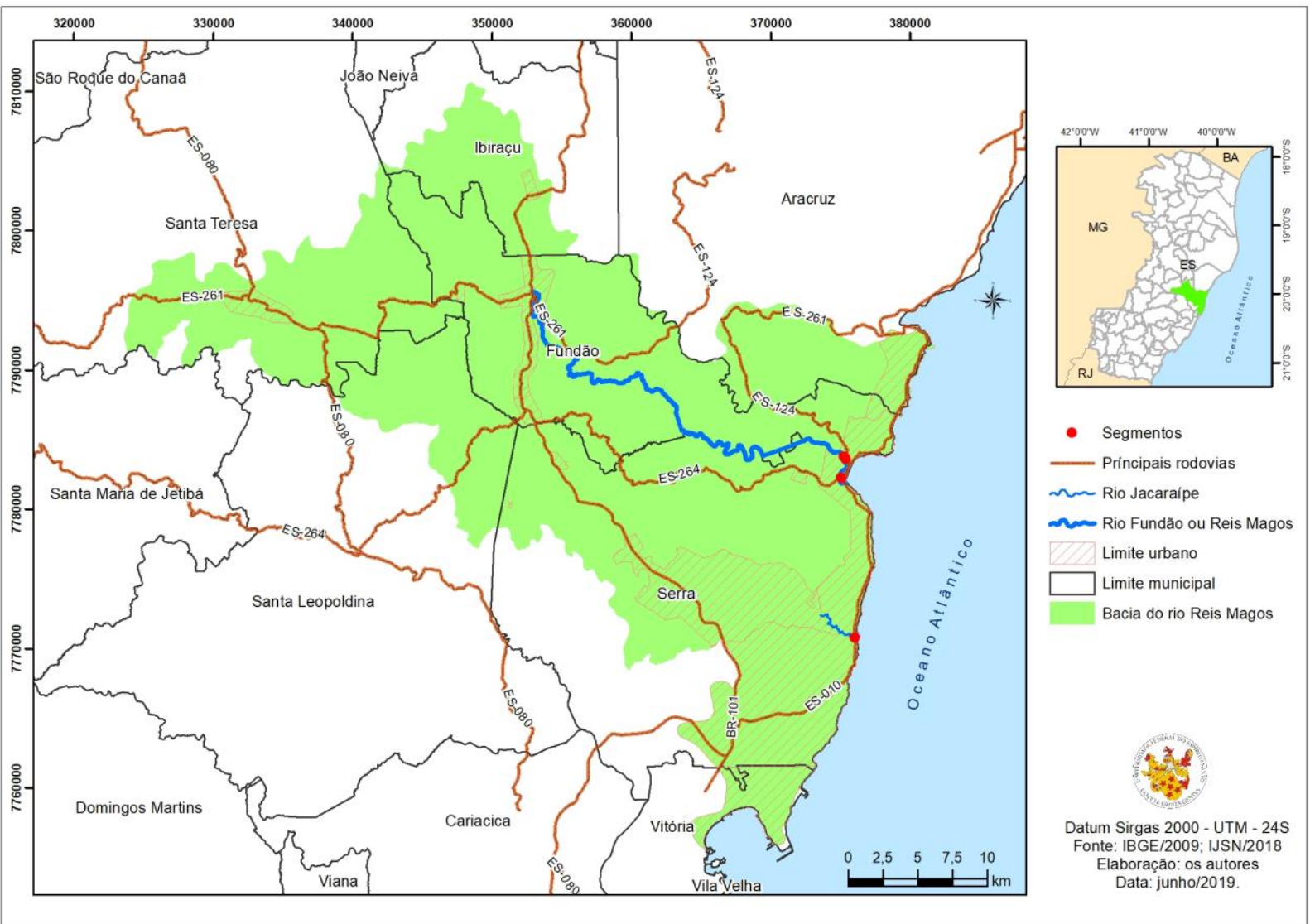

Elaborado pelos autores/2019.

A BHRRM possui grande importância socioambiental tanto para o abastecimento de água quanto para a manutenção da diversidade da flora e da fauna na área de sua bacia, potencializando diversas atividades econômicas como a pesca, a agropecuária e o turismo, além de ser uma importante fonte de abastecimento de água dos Municípios da Serra e de Fundão.

O município da Serra, possui uma área territorial de $547,631 \mathrm{~km}^{2} \mathrm{com}$ população estimada para 2019 , de 517.510 habitantes distribuídos em uma densidade demográfica de 741,85 hab/ $/ \mathrm{km}^{2}$. Por outro lado, Fundão possui área territorial de $286,854 \mathrm{~km}^{2}$ com população estimada também para o ano de 2019 , de 21.509 habitantes e densidade demográfica de 58,97 hab/km² (IBGE, 2019).

Esses dois municípios possuem características distintas, do ponto de vista socioeconômico, pois Serra, refere-se ao maior Município da RMGV, com área urbana expressiva, nos últimos anos, tem sido fortemente industrializada; já Fundão, em grande parte, ainda é caracterizada por áreas rurais com uma pequena parte urbana (Figuras 4 e 5 ).

Caminhos de Geografia Uberlândia

v. 21, n. 73

Mar/2020

p. $492-505$

Página 495 
Avaliação visual rápida de rios urbanos: o caso do baixo curso da bacia hidrográfica do Rio Reis Magos e do Rio Jacaraípe, Espírito Santo
Fabricio Holanda do Nascimento Amanda Fernandes Silva Silênia de Azevedo Silveira Rangel Fernanda Barboza dos Santos

Figura 2 - Declividades na bacia hidrográfica do Rio Reis Magos.

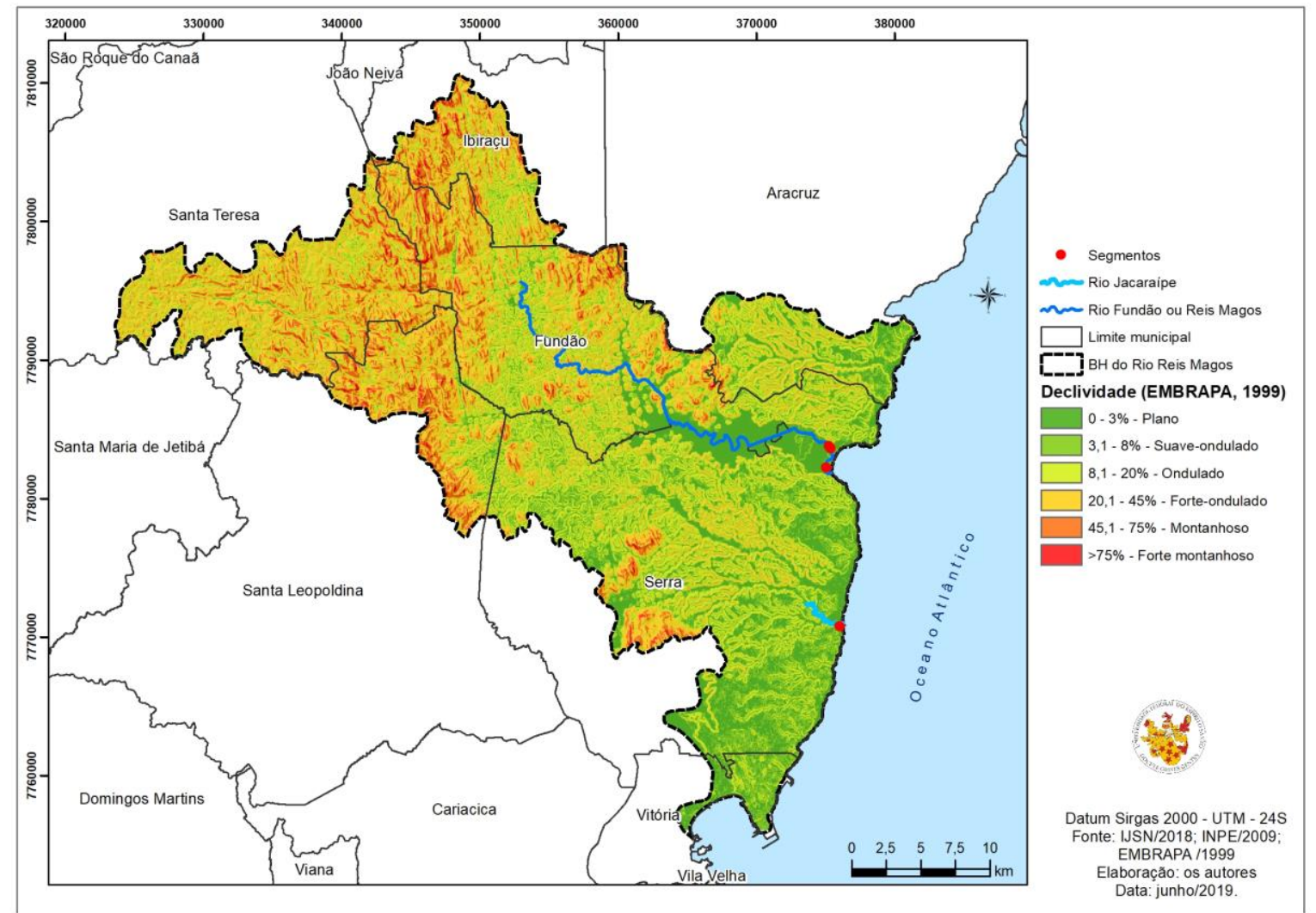

Elaborado pelos autores/2019.

Figura 3 - Uso e cobertura da terra na bacia hidrográfica do Rio Reis Magos.

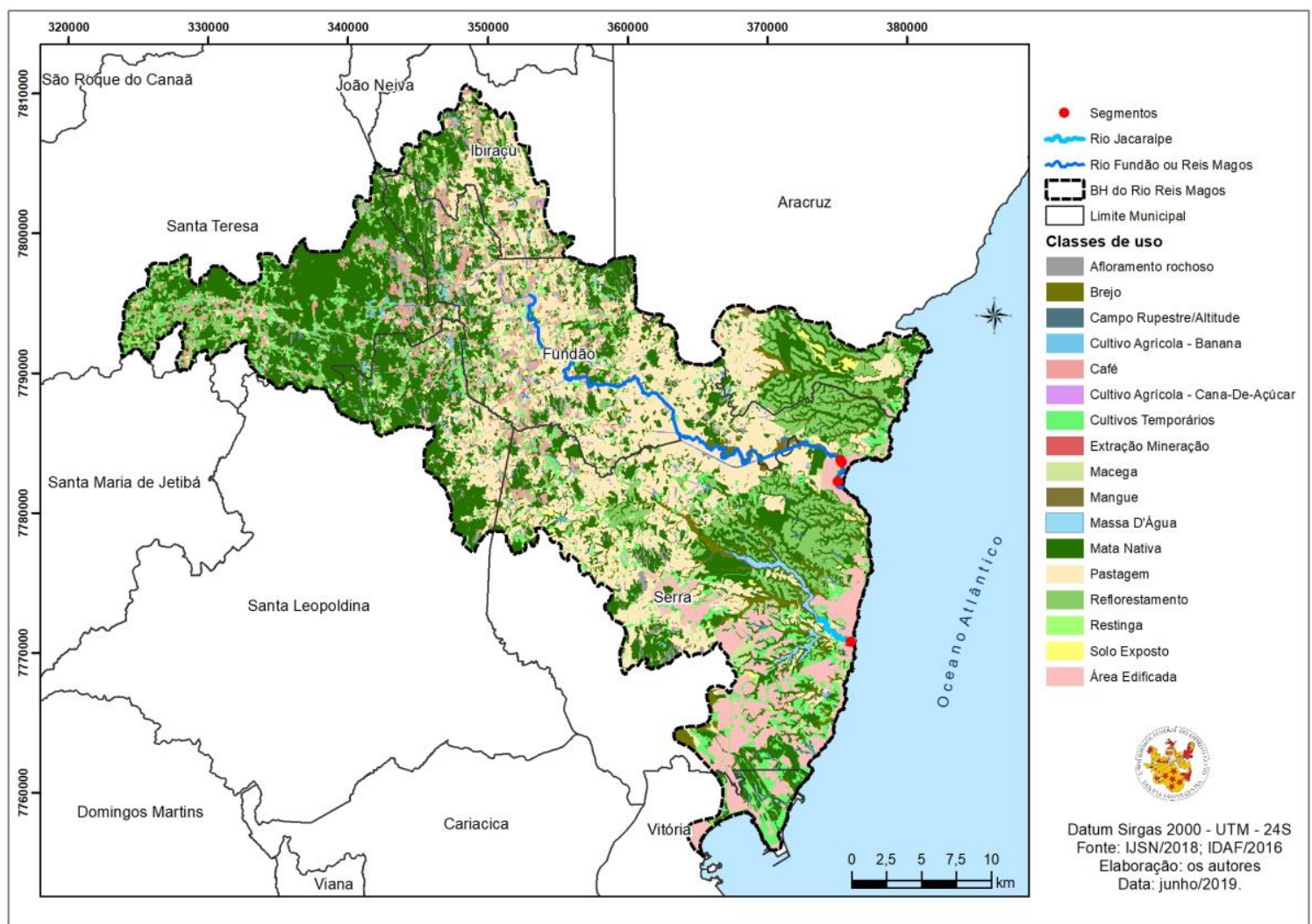

Elaborado pelos autores/2019.

\begin{tabular}{llllll}
\hline Caminhos de Geografia & Uberlândia & v. 21, n. 73 & Mar/2020 & p. 492-505 & Página 496
\end{tabular}


Avaliação visual rápida de rios urbanos: o caso do baixo curso da bacia hidrográfica do Rio Reis Magos e do Rio Jacaraípe, Espírito Santo
Fabricio Holanda do Nascimento Amanda Fernandes Silva Silênia de Azevedo Silveira Rangel Fernanda Barboza dos Santos

Tabela 1 - Estatística de uso e cobertura da terra na bacia hidrográfico do Rio Reis Magos.

\begin{tabular}{c|c|c}
\hline Classe & Area & Percentual \\
\hline Mata Nativa & $\mathbf{3 6 3 , 1 1}$ & $\mathbf{3 1 , 4 6}$ \\
Brejo & 30,92 & 2,68 \\
Afloramento Rochoso & 24,81 & 2,15 \\
Pastagem & $\mathbf{2 9 7 , 0 9}$ & $\mathbf{2 5 , 7 4}$ \\
Macega & 32,77 & 2,84 \\
Solo Exposto & 9,70 & 0,84 \\
Outros & 67,83 & 5,88 \\
Massa D'Água & 14,46 & 1,25 \\
Area Edificada & $\mathbf{6 5 , 9 4}$ & $\mathbf{5 , 7 1}$ \\
Reflorestamento - Eucalipto & $\mathbf{1 0 9 , 2 0}$ \\
Restinga & 0,07 & 0,01 \\
Cultivo Agrícola - Outros Cultivos Permanentes & 7,32 & 0,63 \\
Reflorestamento - Seringueira & 6,91 & 0,60 \\
Extração Mineração & 0,21 & 0,02 \\
Cultivo Agrícola - Café & 59,19 & 5,13 \\
Cultivo Agrícola - Cana-De-Açúcar & 0,14 & 0,01 \\
Mangue & 2,36 & 0,20 \\
Campo Rupestre/Altitude & 0,31 & 0,03 \\
Cultivos Temporários & 62,00 & 5,37 \\
\hline Total & $\mathbf{1 1 5 4 , 3 3}$ & $\mathbf{1 0 0}$ \\
\hline
\end{tabular}

Fonte - IJSN/2012/2015. Organizado pelos autores/2019.

Figura 4 - Segmento A sobre imagem de satélite na foz do Rio Jacaraípe, Serra/ES.

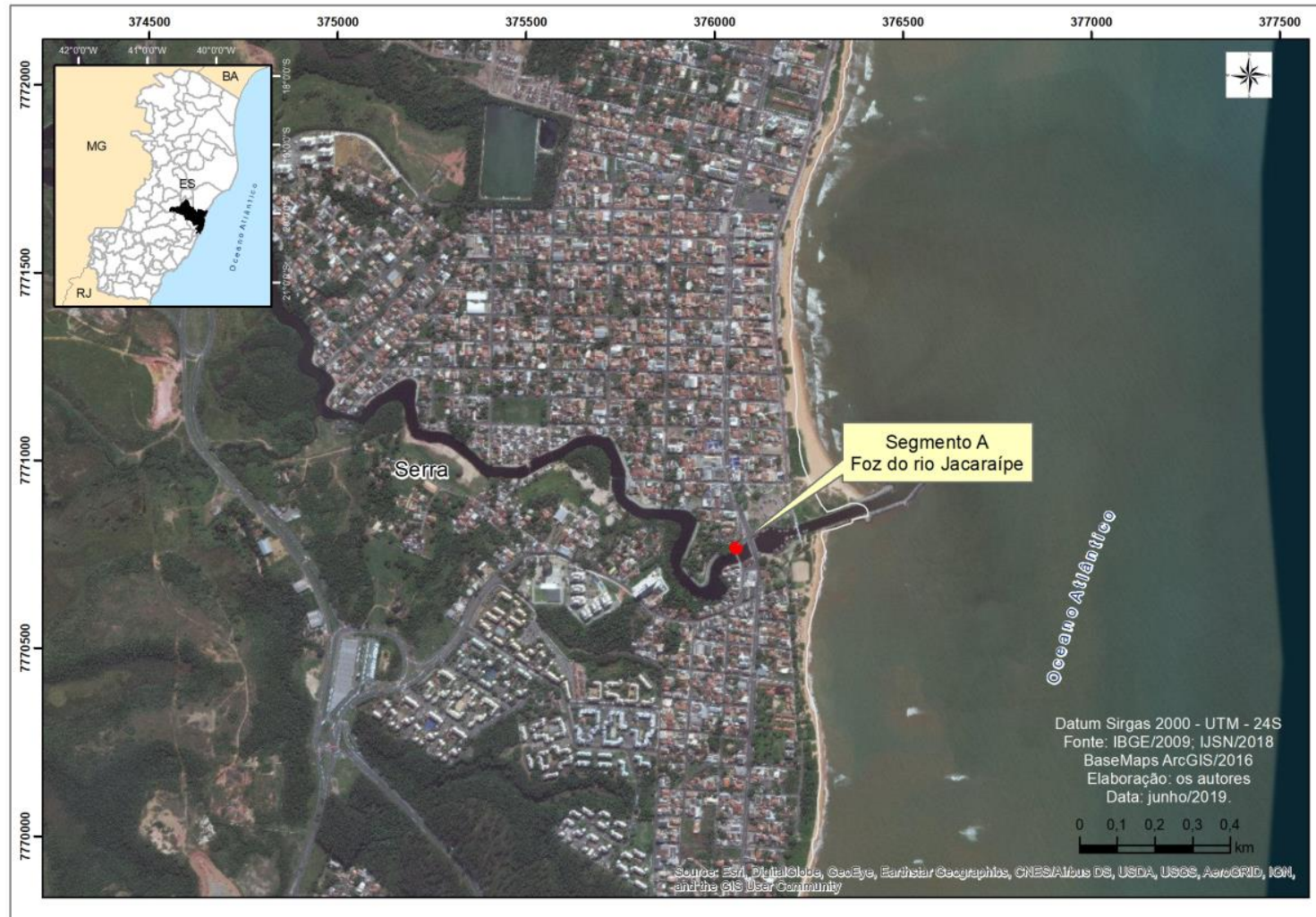

Elaborado pelos autores/2019.

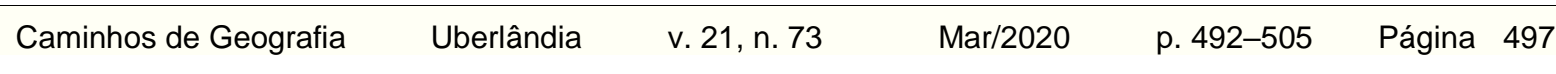


Avaliação visual rápida de rios urbanos: o caso do baixo curso da bacia hidrográfica do Rio Reis Magos e do Rio Jacaraípe, Espírito Santo
Fabricio Holanda do Nascimento Amanda Fernandes Silva Silênia de Azevedo Silveira Rangel Fernanda Barboza dos Santos

Figura 5 - Segmentos B, C e D sobre imagem de satélite no baixo curso do Rio Reis Magos, Fundão/ES.

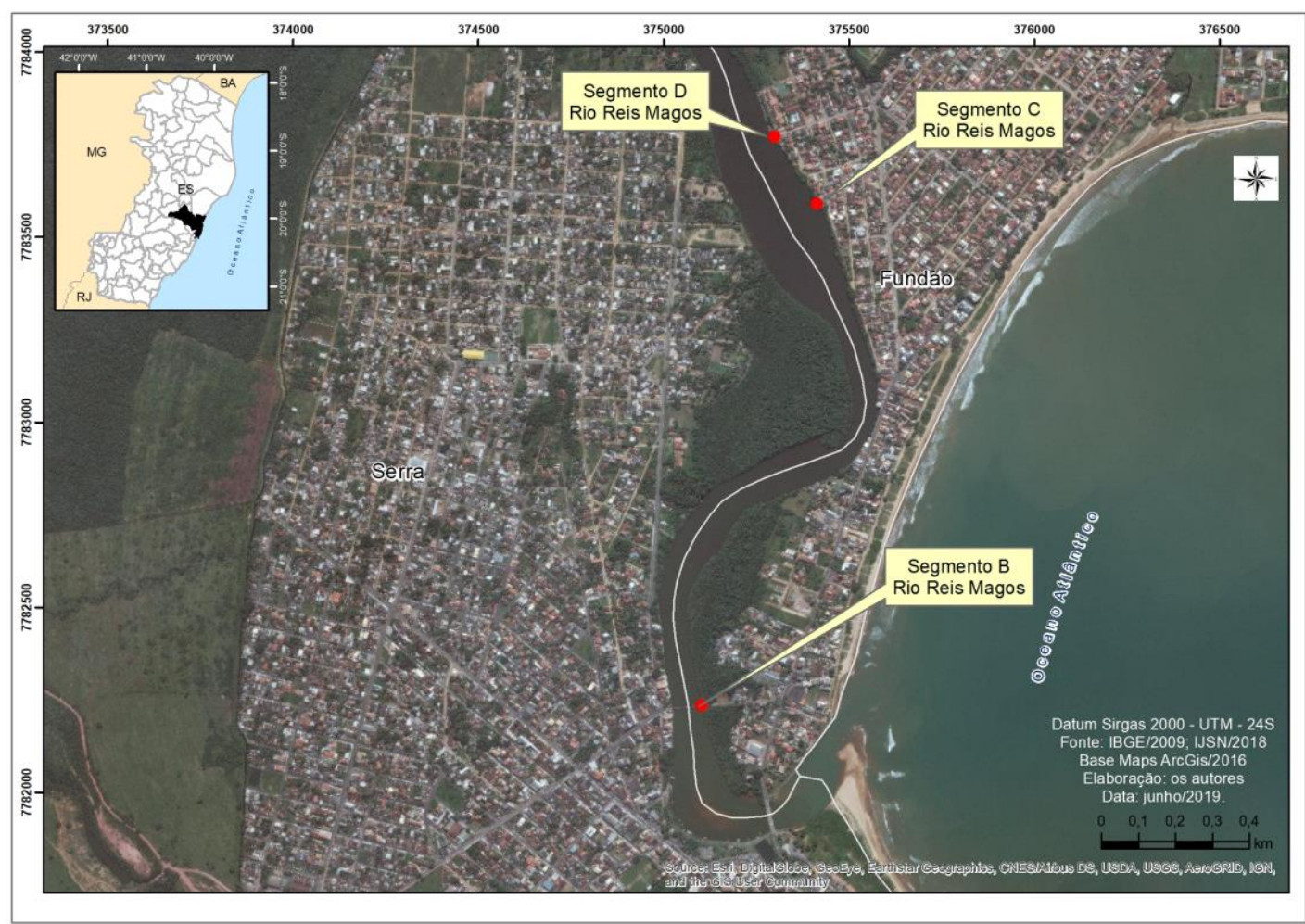

Elaborado pelos autores/2019.

\section{Materiais e Métodos}

Para que os objetivos desta pesquisa fossem alcançados, houve a necessidade de dividi-la em, pelo menos, três fases entre trabalhos de gabinete e trabalhos in situ.

A primeira fase, caracterizada pelo trabalho de gabinete, refere-se à leitura de referencial teóricometodológico, a fim de fundamentar a pesquisa acerca dos seus conceitos norteadores, como a geomorfologia fluvial, os sistemas fluviais, a sociogeomorfologia, a metodologia dos PAR's, entre outros. Ainda nessa fase, foram adquiridas as bases cartográficas utilizadas para a confecção de mapas, por meio de sites de instituições responsáveis, como Instituto Jones dos Santos Neves (IJSN), Instituto Brasileiro de Geografia e Estatísticas (IBGE), Instituto Nacional de Pesquisas Espaciais (INPE) e Geobases (Figura 6). O Quadro 1 refere-se aos dados cartográficos utilizados e às características de cada um.

Quadro 1 - Base cartográfica utilizada para os mapas.

\begin{tabular}{|c|c|c|c|c|}
\hline Dado & Tema & Fonte & Ano & $\begin{array}{c}\text { Escala / } \\
\text { Resolução }\end{array}$ \\
\hline Limite Estadual & Unidades da Federação & IBGE & 2009 & $1: 100.000$ \\
\hline Limite Municipal & Município & IJSN/CGEO & 2018 & $1: 15.000$ \\
\hline Limite de Bairro & Bairros & IJSN/CGEO & 2014 & $1: 15.000$ \\
\hline $\begin{array}{c}\text { Limite de bacia } \\
\text { hidrográfica }\end{array}$ & Otto_bacias & IJSN/IEMA & 2014 & $1: 15.000$ \\
\hline Trecho Rodoviário & Rodovia & IJSN/CGEO & 2014 & $1: 15.000$ \\
\hline $\begin{array}{c}\text { Trecho Drenagem } \\
\text { RMGV }\end{array}$ & Curso d'água & IJSN/IEMA & 2007 & $1: 15.000$ \\
\hline $\begin{array}{c}\text { Uso e cobertura da } \\
\text { terra }\end{array}$ & Uso e cobertura da terra & IDAF & 2016 & $1: 2.500$ \\
\hline MDE & Topodata & INPE & 2009 & $30 \times 30$ \\
\hline Imagem de satélite & Imagem & $\begin{array}{c}\text { Base de imagem } \\
\text { ArcGIS }\end{array}$ & 2018 & \\
\hline
\end{tabular}

Organizado pelos autores/2019.

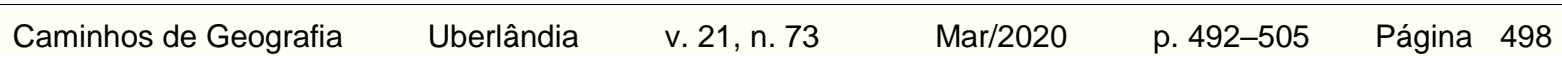


Figura 6 - Fluxograma das etapas da pesquisa.

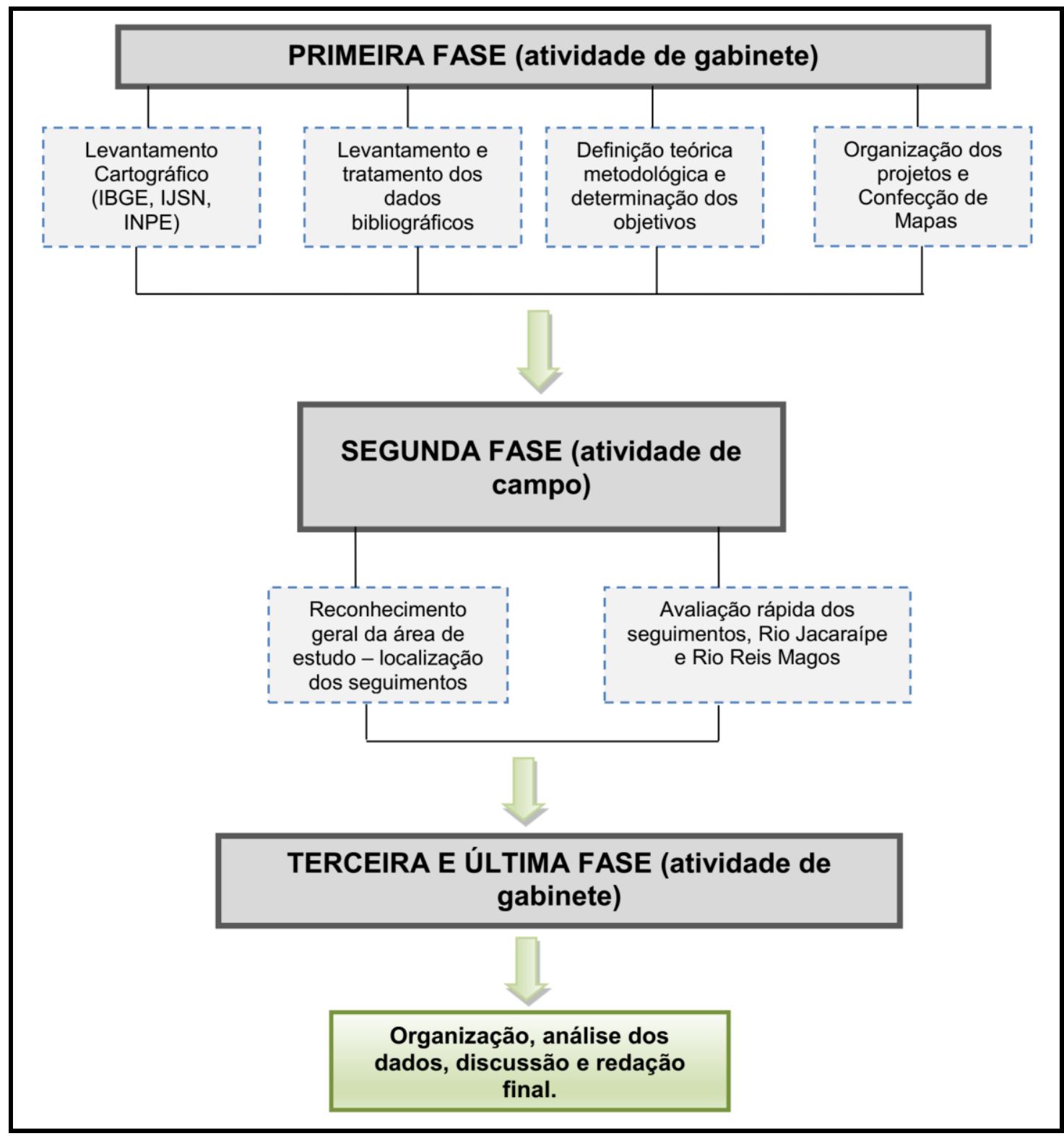

Elaborado pelos autores/2019.

Para a confecção dos mapas, foi aberto um projeto no Sistema de Informações Geográficas (SIG), ArcGIS $10.5^{\circledR}$, extensão ArcMap, a mais utilizada na manipulação de dados espaciais, do Laboratório de Cartografia Geográfica e Geotecnologias, da Universidade Federal do Espírito Santo (LCGGEO/UFES). Este projeto, bem como as bases cartográficas foram configuradas no sistema de projeção Universal Transversa de Mercator (UTM) e Datum de referência SIRGAS 2000, zona 24S. Essas configurações são de suma importância, pois garantem ao mapeamento integridade e padronização cartográfica (FITZ, 2008).

A segunda fase foi dedicada à pesquisa de campo. A investigação consistiu de uma avaliação visual rápida por meio de um questionário/protocolo (

Quadro 2) composto de 14 parâmetros pertinentes às características antrópicas e/ou naturais as quais podem ser identificados visualmente ao longo do rio e nas suas margens. Neste contexto, o trabalho in situ é importante, visto que alguns parâmetros investigados, a exemplo do odor da água, só podem ser identificados em campo.

Utilizou-se os seguintes materiais no campo: caderneta de campo para anotar todas as informações necessárias; mapas para anotar os pontos visitados e as estradas percorridas; máquina fotográfica importante para o registro das imagens que forneçam uma infinidade de detalhes do objeto em estudo -; e, por fim, o Global Positioning System (GPS) - aparelho que capta sinais de satélites que

$\begin{array}{lllll}\text { Caminhos de Geografia } & \text { Uberlândia } & \text { v. 21, n. } 73 & \text { Mar/2020 } & \text { p. } 492-505\end{array}$ Página 499 
Avaliação visual rápida de rios urbanos: o caso do baixo curso da bacia hidrográfica do Rio Reis Magos e do Rio Jacaraípe, Espírito Santo
Fabricio Holanda do Nascimento Amanda Fernandes Silva

Silênia de Azevedo Silveira Rangel Fernanda Barboza dos Santos

estão em órbita em torno da Terra e informa as coordenadas do local onde se está -, cujo aplicativo utilizado foi o Mobile Topographer.

O PAR desenvolvido, que se refere a uma adaptação de Hannaford et al. (1997) para avaliação da diversidade de habitats e posteriormente modificado por Callisto et al. (2002), foi aplicado em quatro segmentos ou pontos de dois importantes rios da Região Metropolitana da Grande Vitória (RMGV), um segmento na foz do Rio Jacaraípe e três segmentos no baixo curso do Rio Reis Magos, entre Serra e Fundão (Figura 1).

$\mathrm{Na}$ foz do Rio Jacaraípe escolheu-se apenas um segmento (A). Esse ponto foi escolhido devido a alguns fatores, como a facilidade de acesso e também a densidade de ocupação humana em torno do ponto, o que pode representar um nível de degradação elevado do trecho em análise. Além disso, foi possível identificar, neste segmento, em especial sobre a ponte onde foi realizada a avaliação, diversas pessoas utilizando o espaço para recreação, como a atividade pesqueira. Os pontos no baixo curso do Rio Reis Magos foram selecionados levando em consideração a facilidade de acesso (segmento B), ocupação e uso humano, e uso misto (segmento C).

Quadro 2 - Protocolo aplicado na avaliação visual rápida no baixo curso do Rio Reis Magos.

\begin{tabular}{|c|c|c|c|c|c|c|}
\hline & \multicolumn{6}{|l|}{ Localização: } \\
\hline & \multicolumn{6}{|l|}{ Data da coleta: } \\
\hline & \multicolumn{6}{|l|}{ Tempo Atmosférico: } \\
\hline & \multicolumn{6}{|l|}{ Responsáveis: } \\
\hline & \multicolumn{4}{|l|}{ Tipo de Ambiente: } & \multirow{2}{*}{\multicolumn{2}{|c|}{$\begin{array}{c}\text { Avaliação } \\
\text { Segmentos }\end{array}$}} \\
\hline & \multirow{2}{*}{ Parâmetro } & \multicolumn{3}{|c|}{ Pontuação } & & \\
\hline & & 3 & 2 & 1 & & \\
\hline 1 & $\begin{array}{l}\text { Tipos de Ocupação nas } \\
\text { margens e proximidades }\end{array}$ & $\begin{array}{l}\text { Vegetação } \\
\text { nativa }\end{array}$ & $\begin{array}{c}\text { Pastagem } \\
\text { agricultura } \\
\text { reflorestamento }\end{array}$ & $\begin{array}{c}\text { Residencial } \\
\text { Comercial e } \\
\text { Industrial }\end{array}$ & & \\
\hline 2 & $\begin{array}{l}\text { Obras e estruturas } \\
\text { hidráulicas }\end{array}$ & Ausente & $\begin{array}{l}\text { Parcialmente } \\
\text { Canalizado } \\
\text { (margens ou } \\
\text { fundo) }\end{array}$ & $\begin{array}{c}\text { Totalmente } \\
\text { Canalizado } \\
\text { e/ou } \\
\text { Tamponado }\end{array}$ & & \\
\hline 3 & $\begin{array}{l}\text { Fontes pontuais de } \\
\text { emissão de efluentes }\end{array}$ & Ausente & $\begin{array}{l}\text { Emissão de } \\
\text { esgoto } \\
\text { doméstico }\end{array}$ & $\begin{array}{l}\text { Emissão de } \\
\text { efluentes de } \\
\text { origem } \\
\text { química } \\
\text { industrial }\end{array}$ & & \\
\hline 4 & Resíduos Sólidos & Ausente & Pouco & Muito & & \\
\hline 5 & Espumas & Ausente & Pouca & Muito & & \\
\hline 6 & $\begin{array}{c}\text { Odor da Água (exceto } \\
\text { Mangue) }\end{array}$ & Ausente & Fraco & Forte & & \\
\hline 7 & Turbidez da Água & Transparente & $\begin{array}{l}\text { Turva / Cor de } \\
\text { Chá forte }\end{array}$ & $\begin{array}{l}\text { Opaca ou } \\
\text { Colorida }\end{array}$ & & \\
\hline 8 & Vegetação Aquática & Ausente & $\begin{array}{c}\text { Presença de } \\
\text { musgos } \\
\text { obstruindo o rio }\end{array}$ & Macrófitas & & \\
\hline 9 & $\begin{array}{c}\text { Proteção/Estrutura das } \\
\text { Margens }\end{array}$ & Protegida & Pouco protegida & Sem Proteção & & \\
\hline 10 & $\begin{array}{c}\text { Cobertura Vegetal } \\
\text { Adjacente }\end{array}$ & Abundante & Esparsa & Ausente & & \\
\hline 11 & $\begin{array}{c}\text { Elementos de retenção no } \\
\text { canal }\end{array}$ & $\begin{array}{l}\text { Pedras troncos } \\
\text { e Folhas }\end{array}$ & Parcial & Ausente & & \\
\hline 12 & $\begin{array}{l}\text { Estabilidade das margens } \\
\text { à erosão e movimentos de } \\
\text { massa }\end{array}$ & Estável & $\begin{array}{l}\text { Parcialmente } \\
\text { Estável }\end{array}$ & Instável & & \\
\hline 13 & $\begin{array}{c}\text { Sombreamento por } \\
\text { Vegetação }\end{array}$ & Total & Parcial & Ausente & & \\
\hline 14 & Uso por animais & Ausente & $\begin{array}{c}\text { Pouco } \\
\text { expressivo }\end{array}$ & Presente & & \\
\hline & & Total & & & & \\
\hline
\end{tabular}

Adaptado de Callisto et al. (2002).

Para a avaliação final dos segmentos, foram calculados os totais da pontuação obtida por cada ponto, levando em consideração que os valores de 2 a 3 referem-se, predominantemente de aspectos naturais, a antrópicos da paisagem; enquanto que a pontuação de número 1 diz respeito às características totalmente antrópicas que podem ser observadas na paisagem. Assim, os segmentos que receberam totais acima de 35 pontos foram classificados em "qualidade boa"; já os segmentos com totais de 30 a 35 foram classificados como "qualidade regular"; e, por fim, os segmentos com totais até 30 foram classificados em "qualidade ruim". Além disso, cada classe recebeu uma cor correspondente, variando de acordo com a escala, passando do verde ao amarelo; por fim, ao vermelho, referindo-se às classes de qualidades boa, regular e ruim, respectivamente.

A terceira e última fase foi dedicada às análises, à interpretação e à discussão dos resultados, bem como à redação final do artigo.

$\begin{array}{lllll}\text { Caminhos de Geografia } & \text { Uberlândia } & \text { v. 21, n. } 73 & \text { Mar/2020 } & \text { p. 492-505 Página } 500\end{array}$


Avaliação visual rápida de rios urbanos: o caso do baixo curso da bacia hidrográfica do Rio Reis Magos e do Rio Jacaraípe, Espírito Santo
Fabricio Holanda do Nascimento Amanda Fernandes Silva

Silênia de Azevedo Silveira Rangel Fernanda Barboza dos Santos

\section{RESULTADOS E DISCUSSÃO}

A pesquisa de campo ocorreu no dia 22 de junho de 2019, no período da tarde, em quatro segmentos, sendo que três desses fazem parte do baixo curso do Rio Reis Magos, localizado entre os Municípios da Serra e de Fundão na RMGV, e apenas um segmento próximo à foz do Rio Jacaraípe, Serra, Espírito Santo.

Segundo o Instituto Nacional de Meteorologia (INMET), no dia da coleta, às $15 \mathrm{~h} 30 \mathrm{~min}$, de acordo com a estação meteorológica do Município da Serra, a temperatura média do ar era de $22{ }^{\circ} \mathrm{C}$, ventos fracos a moderados de direção S-SE, umidade relativa do ar de $77,5 \%$ com o céu totalmente coberto de nuvens com características cumuliformes. Nesse contexto, as condições atmosféricas no dia do trabalho em campo, em 22 de junho de 2019 às 15 horas, embora instáveis, não acarretaram prejuízos na sua execução, que seria impossível caso o tempo atmosférico estivesse chuvoso.

O Quadro 3 refere-se aos resultados das coletas. As cores indicam a classificação dos segmentos avaliados: vermelha para ruim; amarela para regular; e verde para boa. Nesse sentido, parte significativa dos segmentos analisados possui qualidade regular a ruim, possivelmente resultado das ações antrópicas exercidas nas proximidades desses Rios. No segmento A, foz do Rio Jacaraípe, é possível perceber construções residenciais ocupando praticamente as suas margens, além do lançamento de esgotos, fato que gera consequências para o trecho em questão que pode ser evidenciado pela cor da água (Figura 7).

O segmento B faz parte do Rio Reis Magos, no baixo curso. Esse segmento apresenta uma característica bem peculiar, pois uma margem do Rio apresenta densidade de ocupações bastante elevada, cobrindo totalmente a área de preservação permanente (mata ciliar), de outro lado, nota-se uma área de manguezal bem preservada (

Figura 8).

Quadro 3 - Resultados coletados em campo e os pesos atribuídos para cada parâmetro.

\begin{tabular}{|c|c|c|c|c|c|c|c|c|}
\hline & \multirow{2}{*}{\multicolumn{8}{|c|}{ Localizacão: Foz do Rio Jacara }} \\
\hline & & & & & & & & \\
\hline & \multicolumn{8}{|c|}{ Data/hora da coleta: 22/06/2019/15:00 horas } \\
\hline & \multicolumn{8}{|c|}{ Tempo Atmosférico: Instável com probabilidade de chuva acima de $70 \%$} \\
\hline & \multicolumn{8}{|c|}{ Responsáveis: Os autores } \\
\hline & \multicolumn{4}{|c|}{ Tipo de Ambiente: Sistema fluvial } & \multirow{2}{*}{\multicolumn{4}{|c|}{ Avaliação }} \\
\hline & \multirow{2}{*}{ Parâmetro } & \multicolumn{3}{|c|}{ Pontuação } & \multicolumn{2}{|c|}{ Segmentos } & & \\
\hline & & 3 & 2 & 1 & A & B & C & D \\
\hline 1 & $\begin{array}{l}\text { Tipos de Ocupação nas } \\
\text { margens e proximidades }\end{array}$ & $\begin{array}{l}\text { Vegetação } \\
\text { nativa }\end{array}$ & $\begin{array}{c}\text { Pastagem } \\
\text { agricultura } \\
\text { reflorestamento }\end{array}$ & $\begin{array}{c}\text { Residencial } \\
\text { Comercial e } \\
\text { Industrial }\end{array}$ & 1 & $3+1^{*}$ & 3 & $3+1$ \\
\hline 2 & $\begin{array}{l}\text { Obras e estruturas } \\
\text { hidráulicas }\end{array}$ & Ausente & $\begin{array}{l}\text { Parcialmente } \\
\text { Canalizado } \\
\text { (margens ou } \\
\text { fundo) }\end{array}$ & $\begin{array}{l}\text { Totalmente } \\
\text { Canalizado } \\
\text { e/ou } \\
\text { Tamponado }\end{array}$ & 2 & 2 & 3 & 2 \\
\hline 3 & $\begin{array}{l}\text { Fontes pontuais de } \\
\text { emissão de efluentes }\end{array}$ & Ausente & $\begin{array}{l}\text { Emissão de } \\
\text { esgoto } \\
\text { doméstico }\end{array}$ & $\begin{array}{l}\text { Emissão de } \\
\text { efluentes de } \\
\text { origem } \\
\text { química } \\
\text { industrial }\end{array}$ & 2 & 2 & 2 & 2 \\
\hline 4 & Resíduos Sólidos & Ausente & Pouco & Muito & 2 & 2 & 2 & 2 \\
\hline 5 & Espumas & Ausente & Pouca & Muito & 3 & 3 & 3 & 3 \\
\hline 6 & $\begin{array}{c}\text { Odor da Água (exceto } \\
\text { Mangue) }\end{array}$ & Ausente & Fraco & Forte & 2 & 2 & 3 & 1 \\
\hline 7 & Turbidez da Água & Transparente & $\begin{array}{l}\text { Turva / Cor de } \\
\text { Chá forte }\end{array}$ & $\begin{array}{l}\text { Opaca ou } \\
\text { Colorida }\end{array}$ & 2 & 2 & 2 & 2 \\
\hline 8 & Vegetação Aquática & Ausente & $\begin{array}{c}\text { Presença de } \\
\text { musgos } \\
\text { obstruindo o rio }\end{array}$ & Macrófitas & 3 & 3 & 3 & 3 \\
\hline 9 & $\begin{array}{c}\text { Proteção/Estrutura das } \\
\text { Margens }\end{array}$ & Protegida & Pouco protegida & Sem Proteção & 1 & 1 & 3 & 3 \\
\hline 10 & $\begin{array}{c}\text { Cobertura Vegetal } \\
\text { Adjacente }\end{array}$ & Abundante & Esparsa & Ausente & 1 & 2 & 3 & $3+1$ \\
\hline 11 & $\begin{array}{l}\text { Elementos de retenção no } \\
\text { canal }\end{array}$ & $\begin{array}{l}\text { Pedras troncos } \\
\text { e Folhas }\end{array}$ & Parcial & Ausente & 3 & 1 & 1 & 1 \\
\hline 12 & $\begin{array}{l}\text { Estabilidade das margens } \\
\text { à erosão e movimentos de } \\
\text { massa }\end{array}$ & Estável & $\begin{array}{l}\text { Parcialmente } \\
\text { Estável }\end{array}$ & Instável & 3 & 2 & 3 & 3 \\
\hline 13 & $\begin{array}{c}\text { Sombreamento por } \\
\text { Vegetação }\end{array}$ & Total & Parcial & Ausente & 1 & 2 & 2 & 2 \\
\hline 14 & Uso por animais & Ausente & $\begin{array}{c}\text { Pouco } \\
\text { expressivo }\end{array}$ & Presente & 2 & 2 & 2 & 2 \\
\hline \multicolumn{5}{|c|}{ Total } & 28 & 30 & 37 & 34 \\
\hline
\end{tabular}

Elaborado pelos autores/2019.

*Significa que em alguns segmentos foram encontrados aspectos de mais de um parâmetro.

$$
\text { Qualidade Boa } \quad \text { Qualidade Regular }
$$

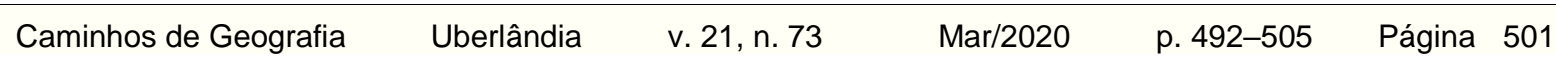


Figura 7 - Fotos do Segmento A na foz do Rio Jacaraípe.

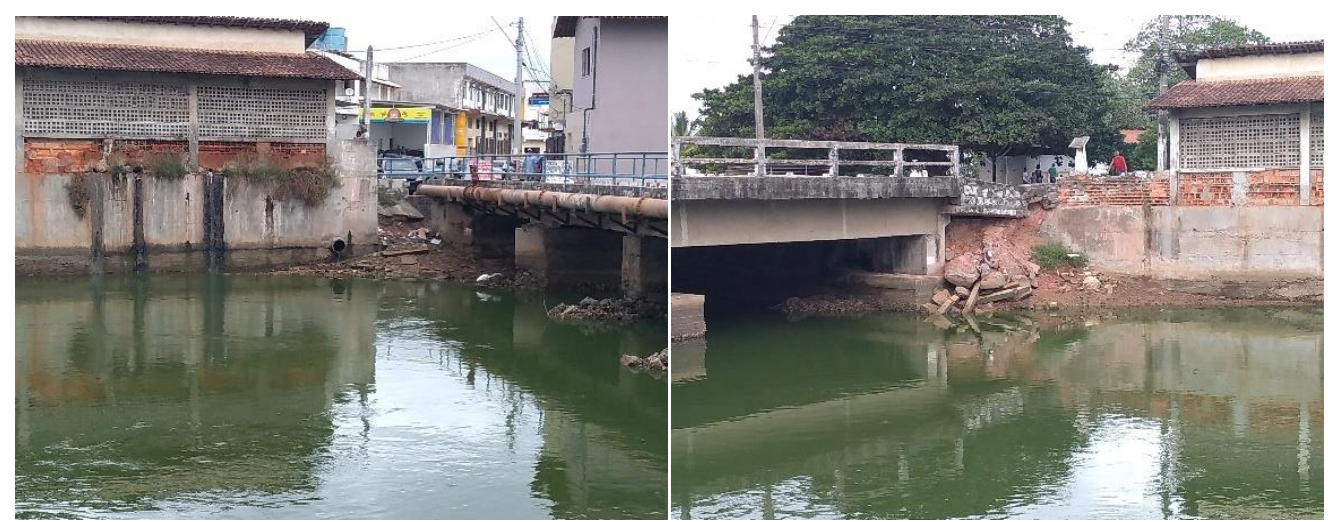

Fonte - Arquivo dos autores/2019.

Figura 8 - Foto do segmento B, baixo curso do Rio Reis Magos evidenciando densa ocupação à esquerda e uma área de manguezal preservada à direita.

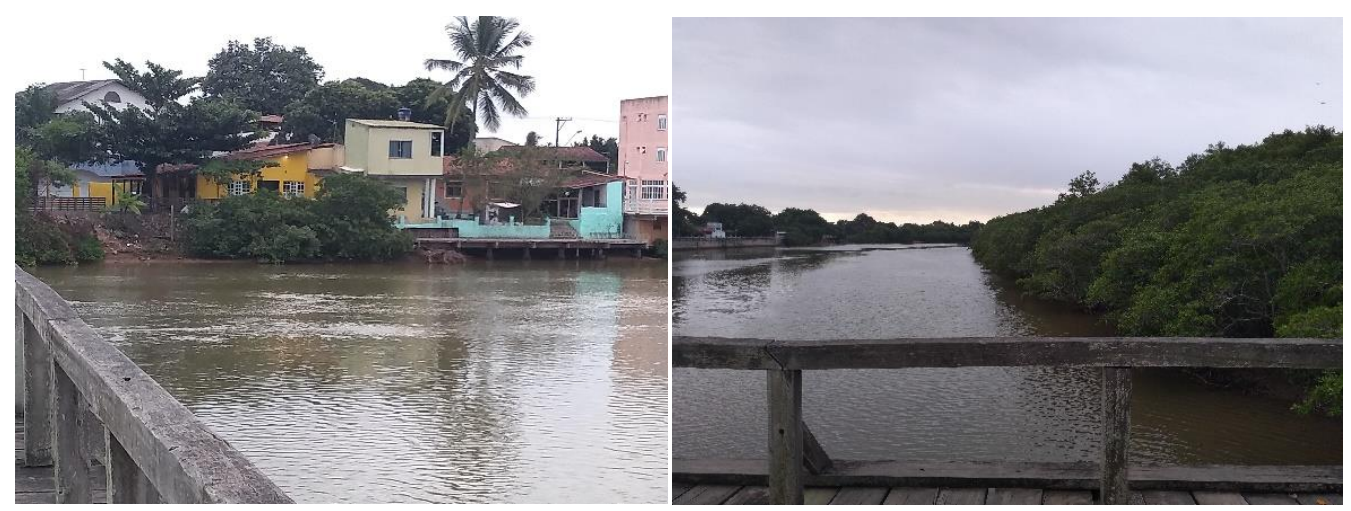

Fonte - Arquivo dos autores/2019.

No segmento $C$, podem ser observadas construções às margens do canal com alguns vestígios de ações humanas, inclusive atividades recreativas praticadas por moradores locais que usam a antiga ponte para a atividade pesqueira, uma evidência da refuncionalização de uma construção que outrora era utilizada apenas para tráfego de automóveis (DETROZ, 2015). Nesse contexto, foram encontrados, de um lado do canal, vestígios de lixo e de restos de construção e, do outro lado, algumas áreas de vegetação conservada. No entanto, a cor da água era característica de "chá forte" e com odor um pouco incômodo, evidenciando um descaso com a conservação e a preservação do rio (Figura 9).

Figura 9 - Fotos do segmento $C$. A foto da esquerda evidencia restos de construções bem próximos ao Rio; e a foto da direita evidencia edificações em uma área que deveria ser ocupada por mata ciliar.

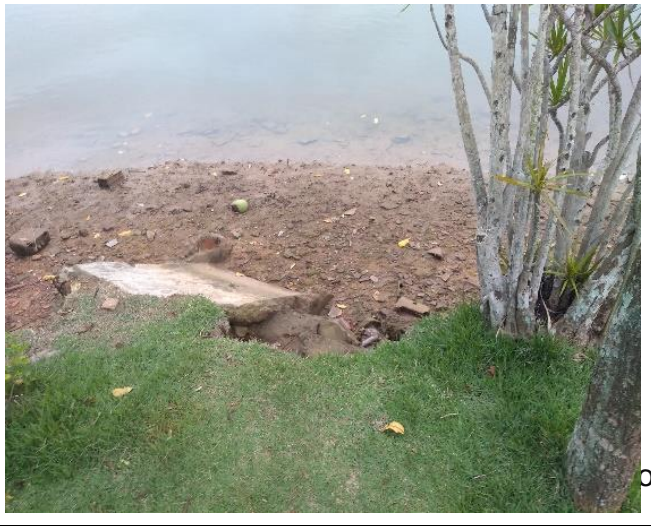

Caminhos de Geografia
Uberlândia

v. 21, n. 73

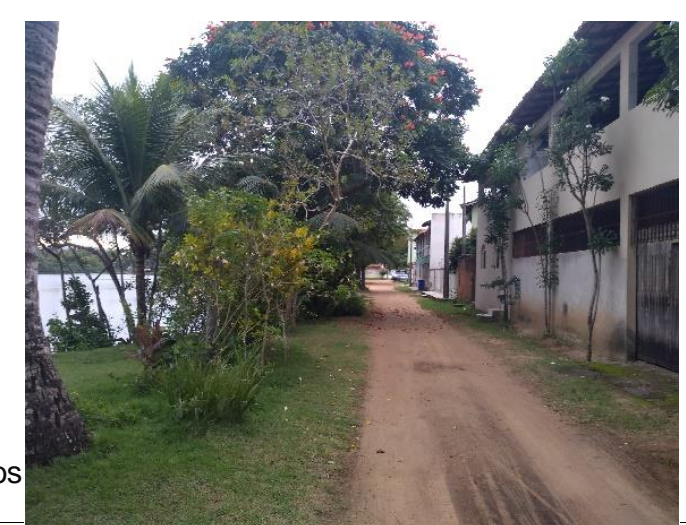

Mar/2020

p. $492-505$

Página 502 
O segmento $D$, o último a ser avaliado, apresentou-se mais criticamente, pois além de ser totalmente ocupado por edificações, efluentes de residências próximas à margem do rio são jogados na água, causando uma série de problemas, como odor característico de um rio poluído e a descaracterização da coloração da água (

Figura 10).

Figura 10 - Fotos do segmento D. À esquerda, lançamento de esgotos no Rio; à direita, casa construída praticamente sobre o Rio Reis Magos.

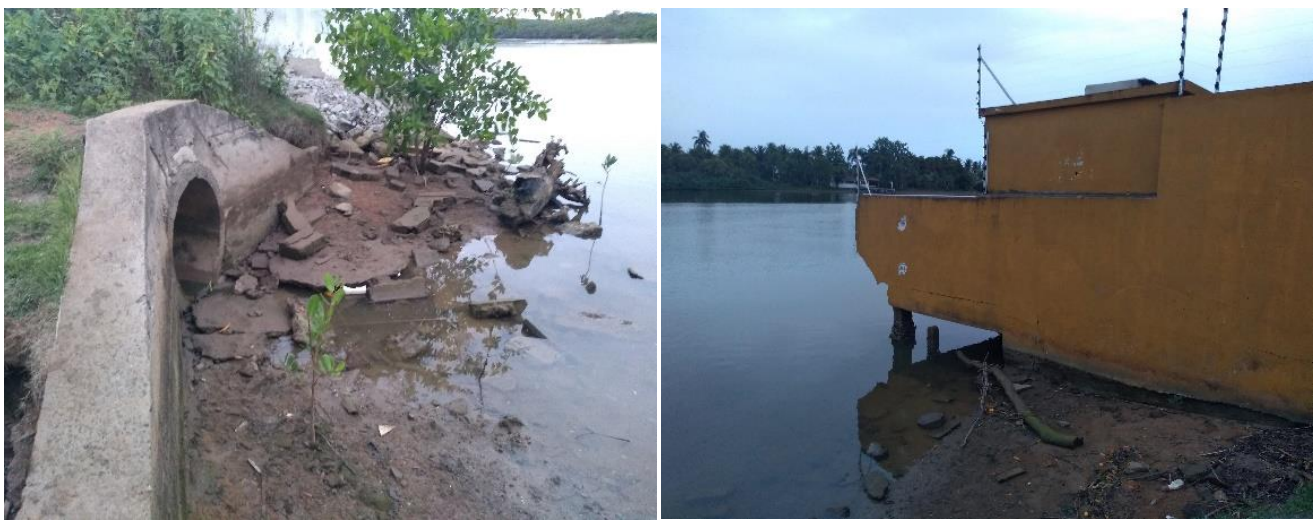

Fonte - Arquivo dos autores/2019.

\section{CONSIDERAÇÕES FINAIS}

Nesta pesquisa, foram analisados quatro segmentos no Estado do Espírito Santo: um na foz do Rio Jacaraípe, Município da Serra; e três no baixo curso do Rio Reis Magos, entre Serra e Fundão, ambos na RMGV. A metodologia empregada (PAR) foi satisfatória, pois permitiu a coleta de dados, a sua aferição e a produção de conhecimento sobre a qualidade visual dos Rios urbanos avaliados.

É importante mencionar que, embora este trabalho refere-se a uma análise visual, o que poderia ter sido desenvolvido a partir do uso e interpretação de imagens de satélites e/ou fotos aéreas, o trabalho in situ foi de grande importância, pois, como já ressaltado, parâmetros como odor da água, uso por animais, e outros, são mais perceptíveis em campo. Venturi (2011) afirma que, embora o Sensoriamento Remoto esteja evoluindo cada vez mais, o trabalho de campo não é invalidado. O trabalho de campo, disserta o autor "[...] representa o contato direto com a realidade, seja como extensão da sala de aula (aula de campo), seja para a realização da pesquisa cientifica" (p.20).

Dos quatro segmentos analisados, apenas um está em condição boa e regular, enquanto que dois foram classificados em condição ruim. Possivelmente, esse resultado seja reflexo das ações antrópicas realizadas nos segmentos, pois o segmento $A$ (condição ruim) é totalmente ocupado por residências e com lançamento de efluentes no canal. Já o segmento $C$ (qualidade boa) é caracterizado por áreas de mata ciliar ainda em estado de conservação, embora possua elementos antrópicos encontrados em determinados pontos de suas margens.

A metodologia empregada é relativamente simples, considerando o seu baixo custo e pouca necessidade de pessoal na execução do campo. Sugere-se como acréscimo de itens, a entrevista aos moradores locais e a análise da qualidade e disponibilidade da água nos segmentos a serem avaliados, conforme a Resolução CONAMA 357/2005 que estabelece os níveis ideais dos parâmetros da água em classes de uso.

Por fim, este tipo de pesquisa pode contribuir para a compreensão e para o entendimento da relação Sociedade e Natureza, notadamente em ambientes fluviais, trazendo conhecimento científico, com o intuito de gerar referencial teórico-prático que possa colaborar com os gestores e a sociedade na resolução de problemas e tomadas de decisões no que se refere aos planejamentos urbano e ambiental.

$\begin{array}{lllll}\text { Caminhos de Geografia Uberlândia } & \text { v. 21, n. } 73 & \text { Mar/2020 } & \text { p. } 492-505 & \text { Página } 503\end{array}$




\section{REFERÊNCIAS BIBLIOGRÁFICAS}

ASHMORE, P. Towards a sociogeomorphology of rivers. Geomorphology. n. 251 p. 149-156, 2015. https://doi.org/10.1016/j.geomorph.2015.02.020

BRASIL. MMA - Ministério do Meio Ambiente. CONAMA - Conselho Nacional do Meio Ambiente. Resolução Conama $n^{\circ} \mathbf{3 5 7 / 2 0 0 5}$. Dispõe sobre a classificação dos corpos de água e diretrizes ambientais para o seu enquadramento, bem como estabelece as condições e padrões de lançamento de efluentes, e dá outras providências.

CALLISTO, M; FERREIRA, W.R; MORENO, P; GOULART, M; PETRUCIO, M. Aplicação de um protocolo de avaliação rápida da diversidade de habitats de ensino e pesquisa (MG-RJ). Revista Acta Limnol Brasileira. Ed. 14 (1): 91-98, 2002.

CHARLTON, R. Fundamentals of Fluvial Geomorphology: 1. ed. Oxon: Routledge, 2008. https://doi.org/10.4324/9780203371084

CUNHA, S. Morfologia de canais urbanos. In: POLETO, C. (Org.). Ambiente e Sedimentos. Porto Alegre: ABRH, 2008, p.329-360.

DETROZ, C.A. Rugosidades e refuncionalização do espaço urbano: o caso do SESC fábrica Pompéia/SP. Monografia (bacharelado em Geografia), Faculdade de Filosofia, Letras e Ciências Humanas, Departamento de Geografia, Universidade de São Paulo, 2015.

EMBRAPA - Empresa Brasileira de Pesquisa Agropecuária. Sistema Brasileiro de Classificação de Solos. Brasília, 1999.

ESRI - Environmental System Research Institute. Banco de imagens de satélites do ArcGIS $10.5^{\circledR}$. Basemaps (2018).

FITZ, P.R. Geoprocessamento sem complicação. São Paulo: Oficina de Textos, 2008. 160 p. ISBN 9788586238826 .

GREGORY, K. J. A natureza da Geografia Física. Bertrand Brasil S.A. São Paulo. 2006.

HANNAFORD, M.J; BARBOUR, M.T; RESh, V.H. Training reduces observer variability in visual-based assessments of stream habitat. Journal of the North American Benthological Society. 16(4):853-860. Chicago, $1997 . \quad$ Disponível em <https://www.jstor.org/stable/1468176?readnow=1\#page_scan_tab_contents>, acesso em 24 nov.2019. https://doi.org/10.2307/1468176

IBGE - Instituto Brasileiro de Geografia e Estatística. Bases Cartográficas Contínuas. Limite de Unidade da Federação de 2009. Disponível em <https://www.ibge.gov.br/geociencias/cartas-e-mapas/basescartograficas-continuas.html>, acesso em 23 jun. 2019.

Informações por cidades e estados: município de Fundão, Espírito Santo. População estimada em 2019. Disponível em < https://cidades.ibge.gov.br/brasil/es/fundao/panorama>, acesso em 12/02/2019.

Informações por cidades e estados: município de Serra, Espírito Santo. População estimada em 2019. Disponível em < https://cidades.ibge.gov.br/brasil/es/serra/panorama>, acesso em 12/02/2019.

IDAF - Instituto De Defesa Agropecuária e Florestal do Espírito Santo. Base cartográfica do uso e cobertura da Terra do estado do Espírito Santo (2016). Disponível em $<$ https://geobases.es.gov.br/links-para-mapes1215>, acesso em 23 jun. 2019.

IJSN - Instituto Jones dos Santos Neves. Base cartográfica - Limite de Bairros (2012). Disponível em <http://www.ijsn.es.gov.br/mapas/>, acesso em 27 jun. 2019.

Base cartográfica - Limite Municipal (2018). Disponível em $\overline{<h t t p: / / w w w . j j s n . e s . g o v . b r / m a p a s />, ~ a c e s s o ~ e m ~} 27$ jun. 2019.

Base cartográfica - Ottobacias hidrográficas (2008). Disponível em <http://www.ijsn.es.gov.br/mapas/>, acesso em 27 jun. 2019.

Base cartográfica - Trecho de Rodovias (2012). Disponível em $\overline{<h t t p: / / w w w . i j s n . e s . g o v . b r / m a p a s />, ~ a c e s s o ~ e m ~} 27$ jun. 2019.

$\begin{array}{lllll}\text { Caminhos de Geografia } & \text { Uberlândia } & \text { v. 21, n. } 73 & \text { Mar/2020 } & \text { p. 492-505 Página } 504\end{array}$


INMET - Instituto Nacional de Meteorologia. Previsão do tempo para sua cidade: Previsão do dia 22 de junho de 2019. Disponível em <http://www.inmet.gov.br/portal/s, acesso em 22 junho 2019.

INPE - Instituto Nacional de Pesquisas Espaciais. Banco de Dados Geométricos do Brasil (2009). Folhas 19_405 e 20_405. Disponível em http://www.webmapit.com.br/inpe/topodata/, acesso em 24 jun. 2019.

ROSA, N.M.G; MAGALHÃES JUNIOR, A.P. Aplicabilidade de Protocolos de Avaliação Rápida (PARs) no diagnóstico ambiental de sistemas fluviais: o caso do Parque Nacional da Serra do Gandarela (MG). Caderno de Geografia, v.29, n.57, 2019, ISSN 2318-2962. https://doi.org/10.5752/P.23182962.2019v29n57p441-464

VENTURI, L.A.B. A Técnica e a Observação na Pesquisa. In: VENTURI, L.A.B. (ORG.) Geografia: Técnicas de Campo, Laboratório e Sala de Aula. São Paulo: Editora Sarandi, 2011.

Recebido em: 19/07/2019

Aceito para publicação em: 12/02/2020 